Short Report

\title{
Development of T-cell immunity in a liver and hematopoietic stem cell transplant recipient following coronavirus disease 2019 infection
}

\author{
Mithil Soni $^{\mathrm{a}, *}$, Edoardo Migliori ${ }^{\mathrm{a}, *}$, Amer Assal $^{\mathrm{b}, \mathrm{c}}$, Hei T. Chan $^{\mathrm{b}}$, Rodica Ciubotariu ${ }^{\mathrm{b}}$, Jian B. Pan ${ }^{\mathrm{b}}$, \\ Kara Cicero $^{\mathrm{b}}$, Marcus Pereira ${ }^{\mathrm{d}}$, Markus Y. Mapara ${ }^{\mathrm{a}, \mathrm{c}}$, Pawel Muranski ${ }^{\mathrm{a}, \mathrm{e}, * *}$ \\ ${ }^{a}$ Columbia Center for Translational Immunology (CCTI), Division of Hematology/ Oncology, Columbia University Medical Center, New York, New York, USA \\ ${ }^{\mathrm{b}}$ Columbia University Medical Center/Herbert Irving Comprehensive Cancer Center, New York, New York, USA \\ c Department of Medicine, Blood and Marrow Transplantation and Cell Therapy Program, Columbia University Irving Medical Center, New York, New York, USA \\ ${ }^{\mathrm{d}}$ Department of Medicine, Division of Infectious Disease, Columbia University College of Physicians and Surgeons, New York, New York, USA \\ ${ }^{\mathrm{e}}$ Hematology Branch, National Heart, Lung, and Blood Institute, Bethesda, Maryland, United States.
}

\section{A R T I C L E I N F O}

\section{Article History:}

Received 17 March 2021

Accepted 12 May 2021

\section{Key Words:}

coronaviruses

COVID-19

organ transplant

T cells

\begin{abstract}
A B S T R A C T
The outbreak of coronavirus disease 2019 (COVID-19) has disproportionately affected patients with comorbidities, including recipients of solid organ and hematopoietic stem cell transplants (SCT). Upon recovery from COVID-19, the degree of the immunological protection from reinfection remains unclear. Here we describe a 33-year-old patient with erythropoietic protoporphyria (EPP) who had undergone liver transplantation with splenectomy followed by allogeneic SCT in 2013 after an initial failed liver and umbilical cord transplant. The patient developed mild upper respiratory symptoms in the spring of 2020 and was found to have anti-SARS-CoV2 antibodies suggesting past infection. A comprehensive analysis of $\mathrm{T}$ cell functionality in peripheral blood from this patient revealed robust in vitro responses against SARS CoV2 antigens Spike (S) 1 and 2, membrane (M) and nucleoprotein (NP), comparable to the reactivity against common antigens from CMV, EBV, Ad and BK viruses, while only low reactivity was seen in healthy donors without documented history of COVID-19. Moreover, the patient displayed a marked recognition of counterpart antigens from related human coronaviruses (hCoVs) 229E, OC43, NL63 and HKU1. Thus, despite lifelong immunosuppression, this survivor of COVID-19 retained a remarkable degree of immunocompetence and showed broad-spectrum $\mathrm{T}$ cell memory specific for SARS-CoV2 and related hCoVs including less studied $\mathrm{hCoV} \mathrm{M}$ and NP antigens. The study highlights the role of cellular immunity after natural COVID-19 infection, suggesting broader use of T cell assays as a tool for risk stratification, measurement of immunocompetence and/or post-infection or post-vaccination protection, and possible T cell-based adoptive immunotherapy strategies in high-risk patients.
\end{abstract}

(C) 2021 Published by Elsevier Inc. on behalf of International Society for Cell \& Gene Therapy.

\section{Introduction}

The ongoing coronavirus disease 2019 (COVID-19) pandemic has disproportionately affected older adults and individuals with comorbidities, including solid organ transplant (SOT) and hematopoietic stem cell transplant (SCT) recipients. These patients typically have complex underlying medical conditions affecting multiple organs, and in the case of SOT recipients, lifelong immunosuppression is required to prevent graft loss. Consequently, COVID-19 has had devastating yet highly variable outcomes in a reported series of SOT recipients, including subjects over 10

\footnotetext{
** Correspondence: Pawel Muranski, MD, Columbia Center for Translational Immunology (CCTI), Division of Hematology/Oncology, Columbia University Medical Center, 650 West 168th Street, BB RM 801-D, New York, NY 10032, USA

E-mail address: pjm2170@cumc.columbia.edu (P. Muranski).

* These authors contributed equally to this work.
}

years post-transplant [1,2]. Among liver transplant recipients, high hospitalization rates and an overall case fatality ratio of $12-30 \%$ have been reported in European cohorts [3,4]. Although the severe and fatal cases of COVID-19 attract the most attention, the spectrum of this disease predominantly includes fully recovered survivors with relatively mild infection courses even among highly vulnerable subjects with comorbidities, including transplant recipients. Healthy survivors of COVID-19 develop variable degrees of post-infection humoral immunity evidenced by the presence of antibodies against severe acute respiratory syndrome coronavirus 2 (SARS-CoV-2) antigens upon serological testing [5].

Although cellular adaptive immunity against COVID-19 mediated by $\mathrm{T}$ cells is less understood, emerging data suggest that $\mathrm{T}$-cell responses may be long-lived and crucial in mediating protection against reinfection, possibly well beyond the period of seropositivity [6-10]. The extent and magnitude of humoral and 
cellular immunity in vulnerable transplant recipients who survive COVID-19 remain poorly characterized [11]. Here the authors report the case of an SOT and bone marrow transplant recipient with evidence of SARS-CoV-2 infection. The authors performed a comprehensive analysis of in vitro T-cell responses to SARS-CoV-2 and other viruses via microculture prime/expansion methodology previously developed in the authors' laboratory as a measure of immunocompetence in subjects with John Cunningham virusassociated progressive multifocal leukoencephalopathy [12,13]. This technique expands even the rare memory precursors from seropositive subjects and was originally used at a large scale for generation of clinical-grade virus-specific T cells targeting simultaneously multiple epitopes for adoptive immunotherapy application. The ability to target common latent viruses, including cytomegalovirus (CMV), Epstein-Barr virus (EBV), adenovirus (AdV) and BK virus, was evaluated and compared with responses against the immunodominant antigens from SARS-CoV-2 to understand COVID-19-induced post-infection immunological memory in the context of overall anti-viral immunity in this lifelong immunosuppressed patient. Furthermore, the authors studied the responses against structurally related counterpart antigens from non-SARS human coronaviruses (hCoVs) 229E, OC43, NL63 and HKU1, which are commonplace respiratory pathogens associated with self-limiting upper respiratory tract infections ("common cold") in healthy individuals but capable of causing serious lower respiratory tract infections and prolonged shedding in vulnerable subjects with comorbidities [14-16]. T-cell responses against those viruses have not been well characterized.

\section{Methods}

\section{Sample collection and cryopreservation}

Peripheral blood was collected after obtaining informed consent from health care workers (healthy donors) and patients with hematological disorders with and without documented history of COVID19 under the Columbia University Medical Center Institutional Review Board-approved study of T-cell immunity against CoVs. Peripheral blood mononuclear cells (PBMCs) were isolated using gradient separation and cryopreserved in CryoStor CS10 freezing medium (STEMCELL Technologies, Vancouver, Canada). For this analysis, samples from the three randomly selected seronegative health care workers were used as controls.

\section{In vitro T-cell expansion and measurement of anti-viral activity}

Membrane (M) and nucleocapsid protein (NP) peptide libraries (peptide mixes) derived from hCoVs 229E, OC43, NL63 and HKU1 were custom synthesized at 70\% purity (peptides \& elephants $\mathrm{GmbH}$, Hennigsdorf, Germany). All other peptide mixes were purchased from commercial vendors (JPT Peptide Technologies GmbH, Berlin, Germany, and Miltenyi Biotec, Bergisch Gladbach, Germany). Cryopreserved PBMCs were thawed and pulsed with peptide libraries (final concentration of $1 \mu \mathrm{g} / \mathrm{mL}$ ) and cultured in AIM V medium (Thermo Fisher Scientific, Waltham, MA, USA) supplemented with inactivated $5 \%$ human serum and IL-7 at $10 \mathrm{ng} / \mathrm{mL}$ (PeproTech, Rocky Hill, NJ, USA) in 96-well U-bottom plates. Fresh medium supplemented with IL-7 and IL-2 at $30 \mathrm{IU} / \mathrm{mL}$ (PeproTech) was replenished every 3 days. On day 14, the expanded T cells were restimulated with cognate peptide mixes for $6 \mathrm{~h}$ in the presence of brefeldin $A$ and monensin A (BD Biosciences, San Jose, CA, USA) per the manufacturer's instructions. Intracellular cytokine staining was performed using a BD Cytofix/Cytoperm kit (BD Biosciences) following the manufacturer's instructions and measured by flow cytometry. The following surface markers and cytokines were evaluated: viability (Vivid;
Invitrogen, Waltham, MA, USA) and CD3, CD4, CD8, TNF $\alpha$, IFN- $\gamma$, IL-2 and granzyme B (BioLegend, San Diego, CA, USA). Flow cytometry results were analyzed using FlowJo software (BD Biosciences).

\section{Case Presentation}

The patient is a 33-year-old male with erythropoietic protoporphyria (EPP), originally diagnosed at the age of 5. EPP is an inborn deficiency of ferrochelatase in which protoporphyrin accumulates within the bone marrow and hepatocytes, causing direct hepatobiliary toxicity [17]. The patient developed liver cirrhosis at the age of 18 despite medical management with hemin and plasmapheresis. Consequently, in 2010 he underwent liver transplantation at the age of 20 , but the hepatic damage from EPP recurred. Two years later, the patient underwent a double cord allogeneic SCT with the intention of preventing further liver injury. However, SCT was unsuccessful because of primary graft failure. Over the next 3 years, the patient experienced gradual progression of liver disease with the development of portal hypertension and hypersplenism, further exacerbating pancytopenia. In 2013, the patient received a second orthotopic liver transplant with splenectomy followed by a second allogeneic SCT 5 months later. The donor for the second SCT was his HLA-matched sibling, and the conditioning regimen included fludarabine, melphalan and alemtuzumab. Protoporphyrin levels, liver enzymes and blood counts normalized following simultaneous transplantation. The post-SCT course was complicated by CMV and EBV reactivations, respiratory syncytial virus and several bacterial infections. A single episode of acute cellular rejection occurred approximately 18 months after orthotopic liver transplant but was successfully controlled with steroids and mycophenolate. By 2020, the patient was stable on tacrolimus alone.

On routine follow-up in November 2020, and after recalling a mild upper respiratory illness in the spring of 2020, the patient was found to have positive anti-SARS-CoV-2 nucleocapsid protein antibodies. No polymerase chain reaction was performed at the time of his respiratory symptoms.

After the patient provided informed consent, peripheral blood samples were obtained. Thawed PBMCs were primed with peptide mixes spanning the full length of the viral antigens and cultured for 14 days in medium containing IL-7 and IL-2. Antigen specificity for the resulting T-cell populations was tested upon restimulation with cognate viral antigens. First, the authors tested immune responses against a panel of viral pathogens that commonly affect immunocompromised transplant recipients. The following targets were evaluated: CMV pp65 and IE-1, BK large T and viral protein 1, EBV BZLF1 and EBNA1 and AdV penton (Ad5). Antigen-specific polyfunctional cytokine release was observed within both $\mathrm{CD} 4^{+}$and $\mathrm{CD} 8^{+}$compartments, depending on the viral target, in what was likely a donor-specific pattern (Figure 1). The authors found robust reactivity against both CMV antigens, BK large T and viral protein 1 and AdV penton. However, less potent reactivity specific for the two tested EBV peptide mixes was seen. Overall, the authors concluded that this complex patient with a history of SOT, splenectomy and allogeneic SCT retained a remarkable degree of immunocompetence.

Next, the authors evaluated T-cell responses against the immunodominant structural proteins from SARS-CoV-2, including spike (S) 1 and 2, M and NP. Surprisingly, the authors observed remarkable activity against all studied anti-genic targets, especially within the $\mathrm{CD} 4^{+}$T-cell compartment (Figure 2A,B), whereas very little activity was seen in randomly selected otherwise healthy seronegative health care workers (Figure 2C). The highest reactivity was seen against S2 (26.9\%) followed by NP (13.53\%), M (12.47\%) and S1 (11.73\%). Thus, the magnitude of the observed reactivity was comparable to the well-documented immunodominant components of CMV and BK virus (Figure 1), indicating development of robust multi-epitopespecific post-infection cellular immunity, despite active immunosuppression. Since SARS-CoV-2 is a beta-CoV, the authors hypothesized that the post-COVID-19 immunity might extend to other related 


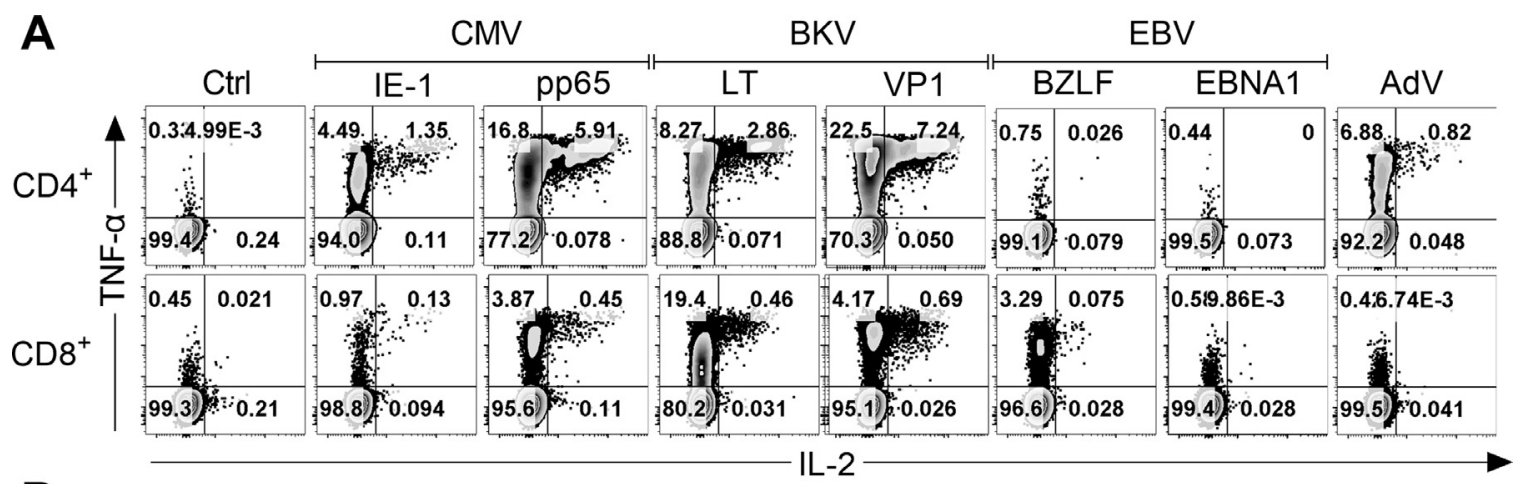

B

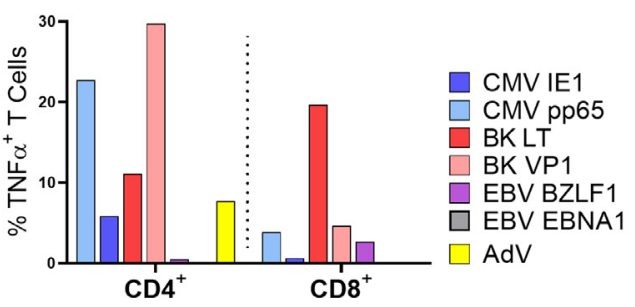

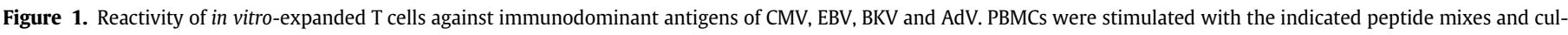

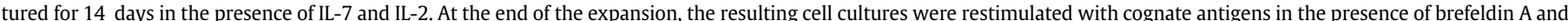

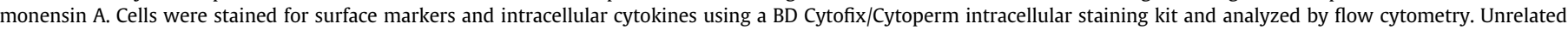

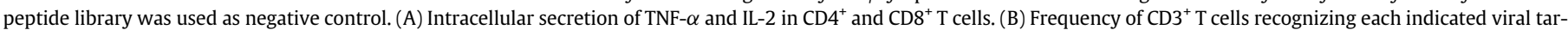
get in $\mathrm{CD}^{+}$and $\mathrm{CD}^{+} \mathrm{T}_{\text {-cell }}\left(\mathrm{CD}^{+}{ }^{+}\right.$) compartments. Ad5, AdV penton; BKV, BK virus; Ctrl, control; LT, large T; VP1, viral protein 1.

members of the hCoV family. Therefore, the authors evaluated immune responses against beta-hCoVs OC43 and HKU1 as well as alpha-hCoVs 229E and NL63. Indeed, upon testing against the custom synthesized panel of peptide libraries, marked immunological reactivity was observed against S1, S2, NP and M antigens from all evaluated hCoVs, with the most profound responses revealed in the $\mathrm{CD} 4^{+}$ T-cell compartment targeting the NP antigen (range, 9.64-14.1\%) followed by S1 (range, 10.1-6.31\%) (Figure 2A,B,D), whereas relatively lower activity was seen in seronegative healthy donors (Figure 2C, D). Activity within the $\mathrm{CD} 8^{+} \mathrm{T}$-cell compartment was seen against NP and $\mathrm{M}$ antigens derived from alpha-hCoVs 229E and NL63, but only minimal activity was seen against beta-hCoVs, pointing to the inherent differences in immunogenicity between these pathogens. Furthermore, the SARS-CoV-2-specific $\mathrm{CD}^{+}{ }^{+} \mathrm{T}$ cells from this patient retained significant polyfunctionality, including robust ability to secrete IL-2, a feature associated with long-term persistence and lack of exhaustion. Although the subject appeared to be highly capable of mounting immune responses against all tested hCoVs, the magnitude of reactivity was lower than the responses against SARS-CoV2, suggesting that the recent COVID-19 infection played the most significant role in shaping his immune repertoire.

\section{Discussion}

Post-COVID-19 humoral immunity is thought to induce neutralizing antibodies that provide a period of relative protection in convalescent subjects. However, antibody titers and half-lives are highly variable, and some subjects might never mount a detectable antibody response [5]. The role of T-cell immunity in host defenses against SARS-CoV-2 and other hCoVs is less understood, but otherwise healthy COVID-19 and SARS-CoV-1 infection survivors develop potent, long-lived, antigen-specific immunological memory against the immunodominant antigens [7,9,18]. It is therefore imperative to characterize these responses in vulnerable subjects with immunodeficiencies as a tool for gauging the overall immunocompetence and possible degree of long-term protection. It is also possible to exploit the in vitro-generated SARS-CoV-2 T cells for adoptive immunotherapy of COVID-19, as proposed recently by Keller et al. [19].

Patients with a history of SOT and SCT are a highly heterogeneous group with various degrees of immune dysfunction and baseline inflammation, depending on the interval since transplant, conditioning regimen used, other ongoing organ dysfunction and concurrent immunosuppressive therapies. Furthermore, some immunosuppressive pharmacological agents, such as steroids, have been shown to ameliorate COVID-19 symptoms and prevent progression to severe respiratory distress syndrome; however, they may also blunt the development of post-infection immunity or abrogate the response to vaccination.

Overall, the patient described here is considered high risk in terms of risk of infectious complications [20]. Nevertheless, despite severe comorbidities, compounded risk factors and lifelong immunosuppression, the subject survived uncomplicated COVID-19 and was incidentally found to be seropositive upon routine screening.

The authors estimated the T-cell immunity against viral antigens using a highly sensitive functional method of measuring broad T-cell memory responses [12]. The authors' analysis revealed development of highly active cellular immunity against multiple antigens derived from SARS-CoV-2. Strikingly, the magnitude of the SARS-CoV-2-specific T-cell responses was comparable to the well-characterized immunity against CMV, BK virus, AdV and EBV and much higher than that seen in healthy, unexposed controls. Moreover, this COVID-19 survivor had the capability of recognizing antigens from all four nonSARS hCoVs, albeit at a lower magnitude/frequency. Importantly, the authors' analysis extended beyond the S1 and S2 antigens commonly examined in the context of the currently approved anti-COVID-19 vaccines and also included the far less studied $M$ and NP proteins from SARS-CoV-2 and all four common hCoVs, suggesting possible heterological cross-protection against future infections, including emerging mutant variants of SARS-CoV-2 and other members of the CoV family [6]. Recent evidence suggests that there might be a tendency for a milder course of the disease in COVID-19 patients who have recently experienced hCoV-related infections, with some cross- 
A

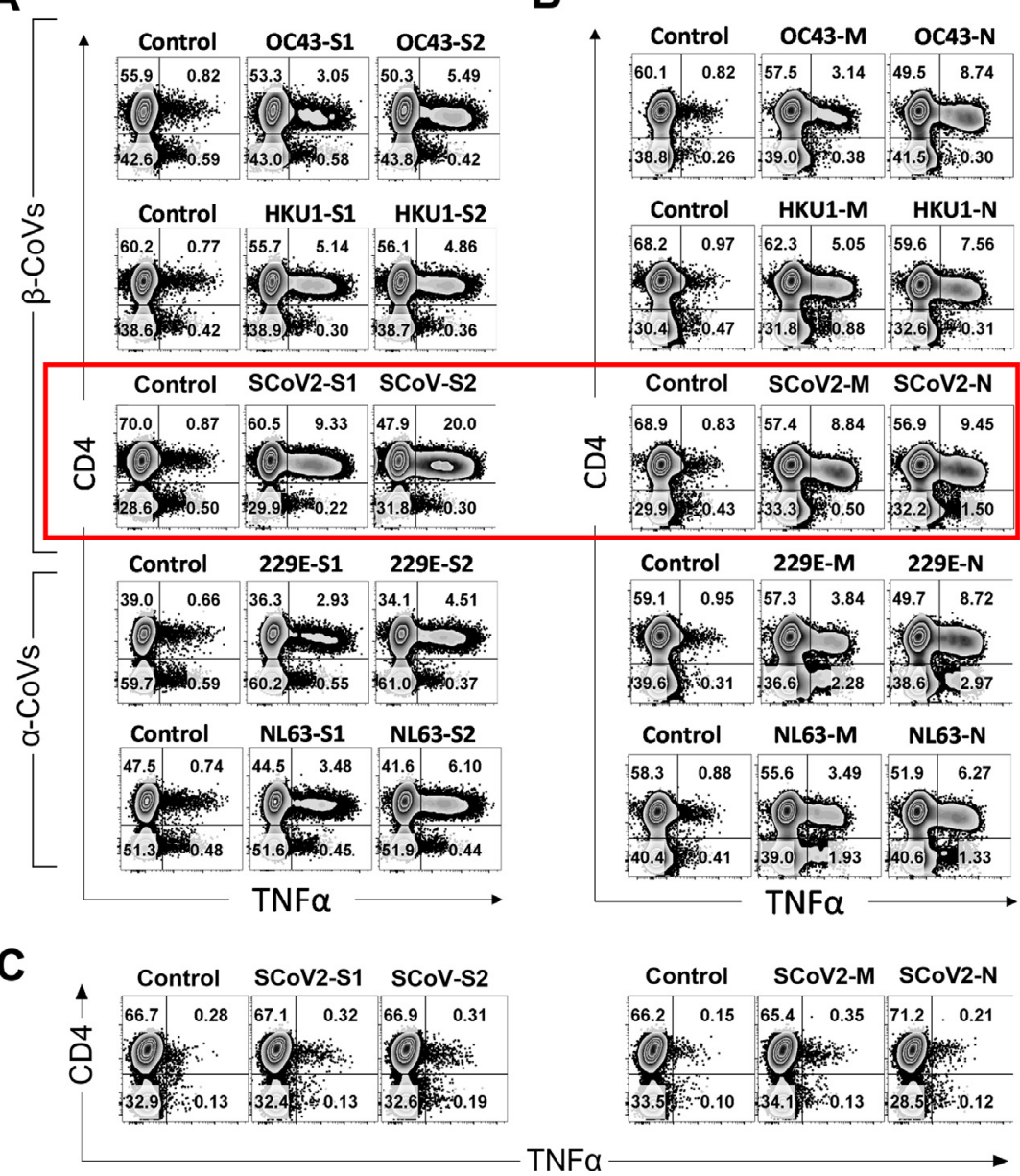

D
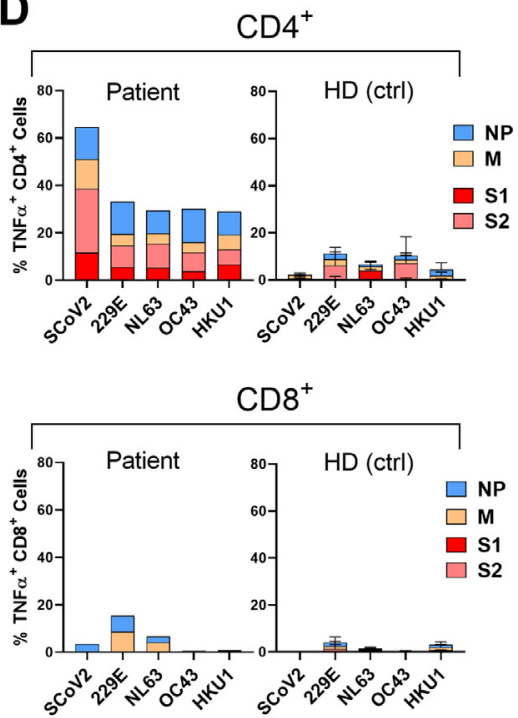

E

Polyfunctionality

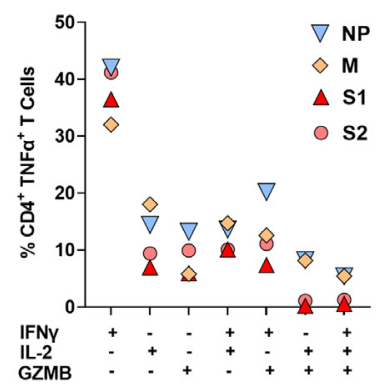

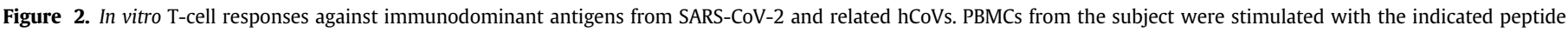

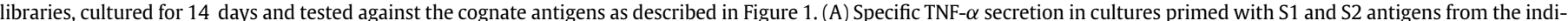

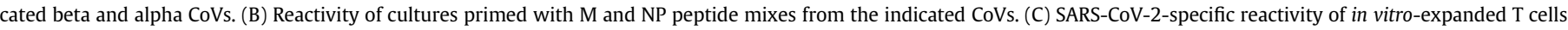

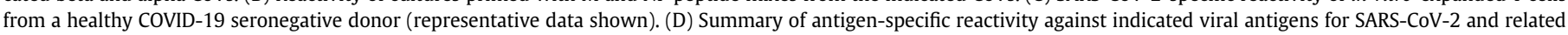

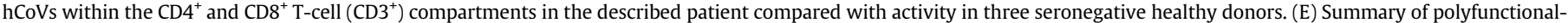
ity among the SARS-CoV-2 antigen-reactive (defined as TNF- $\alpha^{+}$) CD4 ${ }^{+}$T cells specific for the indicated antigens. Ctrl, control; HD, healthy donor; SCoV2, SARS-CoV-2.

reactive antibodies increasing post-COVID [10,21-23]. Unfortunately, in the patient described here, the magnitude of the pre-existing T-cell memory specific for hCoV antigens is unknown. The authors are exploring this question in other healthy and immunodeficient individuals.

\section{Conclusions}

Overall, this case reveals that at least some SOT and SCT recipients maintained on long-term calcineurin inhibitors retain robust T-cell immunocompetence and develop potent cellular immunity against SARS-CoV-2. The authors' strategy allows us to measure these responses in the context of broader anti-viral immunity and use the data for risk stratification. It also allows us to forecast the outcomes of vaccination and provide the rationale for possible use of in vitroexpanded SARS-CoV-2 T cells for adoptive immunotherapy.

\section{Declaration of Competing Interest}

The authors have no commercial, proprietary or financial interest in the products or companies described in this article.

\section{Funding}

This work is supported by Translational Therapeutics (TRx) COVID Award; Accelerating Cancer Therapeutics and BiomedX Programs, CUMC/HICC and Cancer Center Support Grant P30 CA013696 utilizing shared resources including Flow Cytometry Core.

\section{Author Contributions}

Conception and design of the study: PM, MM. Acquisition of data: MS, EM, JP. Analysis and interpretation of data: MS,EM. Drafting or revising the manuscript: MS,EM,RC,KC,MP,PM. All authors have approved the final article.

\section{References}

[1] Pereira MR, Mohan S, Cohen DJ, Husain SA, Dube GK, Ratner LE, Arcasoy S, Aversa MM, Benvenuto LJ, Dadhania DM, Kapur S, Dove LM, Brown Jr. RS, Rosenblatt RE, Samstein B, Uriel N, Farr MA, Satlin M, Small CB, Walsh TJ, Kodiyanplakkal RP, Miko BA, Aaron JG, Tsapepas DS, Emond JC, Verna EC. COVID-19 in solid organ transplant recipients: Initial report from the US epicenter. American journal of transplantation: official journal of the American Society of Transplantation and the American Society of Transplant Surgeons 2020;20(7):1800-8.

[2] Raja MA, Mendoza MA, Villavicencio A, Anjan S, Reynolds JM, Kittipibul V, Fernandez A, Guerra G, Camargo JF, Simkins J, Morris MI, Abbo LA, Natori Y. COVID-19 in 
solid organ transplant recipients: a systematic review and meta-analysis of current literature. Transplant Rev (Orlando) 2021;35(1):100588.

[3] Becchetti C, Zambelli MF, Pasulo L, Donato MF, Invernizzi F, Detry O, Dahlqvist G, Ciccarelli O, Morelli MC, Fraga M, Svegliati-Baroni G, van Vlierberghe H, Coenraad MJ, Romero MC, de Gottardi A, Toniutto P, Del Prete L, Abbati C, Samuel D, Pirenne J, Nevens F, Dufour JF, group C-L. COVID-19 in an international European liver transplant recipient cohort. Gut 2020;69(10):1832-40.

[4] Dumortier J, Duvoux C, Roux O, Altieri M, Barraud H, Besch C, Caillard S, Coilly A, Conti F, Dharancy S, Durand F, Francoz C, Garaix F, Houssel-Debry P, Kounis I, Lassailly G, Laverdure N, Leroy V, Mallet M, Mazzola A, Meunier L, Radenne S, Richardet JP, Vanlemmens C, Hazzan M, Saliba F, R C. French Solid Organ Transplant, F. Groupe de Recherche Francais en Greffe de, COVID-19 in liver transplant recipients: the French SOT COVID registry. Clin Res Hepatol Gastroenterol 2021;45(4):101639.

[5] Gallais F, Velay A, Nazon C, Wendling MJ, Partisani M, Sibilia J, Candon S, Fafi-Kremer S. Intrafamilial Exposure to SARS-CoV-2 Associated with Cellular Immune Response without Seroconversion, France. Emerging infectious diseases 2021;27(1):113-21.

[6] Grifoni A, Weiskopf D, Ramirez SI, Mateus J, Dan JM, Moderbacher CR, Rawlings SA, Sutherland A, Premkumar L, Jadi RS, Marrama D, de Silva AM, Frazier A, Carlin A, Greenbaum JA, Peters B, Krammer F, Smith DM, Crotty S, Sette A. Targets of T cell responses to SARS-CoV-2 coronavirus in humans with COVID-19 disease and unexposed individuals. Cell 2020;181(7):1489-1501.e15.

[7] Dan JM, Mateus J, Kato Y, Hastie KM, Yu ED, Faliti CE, Grifoni A, Ramirez SI, Haupt S, Frazier A, Nakao C, Rayaprolu V, Rawlings SA, Peters B, Krammer F, Simon V, Saphire EO, Smith DM, Weiskopf D, Sette A, Crotty S. Immunological memory to SARS-CoV-2 assessed for up to 8 months after infection. Science 2021;371(6529):eabf4063.

[8] Ni L, Ye F, Cheng ML, Feng Y, Deng YQ, Zhao H, Wei P, Ge J, Gou M, Li X, Sun L, Cao T, Wang P, Zhou C, Zhang R, Liang P, Guo H, Wang X, Qin CF, Chen F, Dong C. Detection of SARS-CoV-2-Specific Humoral and Cellular Immunity in COVID-19 Convalescent Individuals. Immunity 2020;52(6). 971-977 e3.

[9] Ng OW, Chia A, Tan AT, Jadi RS, Leong HN, Bertoletti A, Tan YJ. Memory T cell responses targeting the SARS coronavirus persist up to 11 years post-infection. Vaccine 2016;34(17):2008-14.

[10] Bonifacius A, Tischer-Zimmermann S, Dragon AC, Gussarow D, Vogel A, Krettek U, Godecke N, Yilmaz M, Kraft ARM, Hoeper MM, Pink I, Schmidt JJ, Li Y, Welte T, Maecker-Kolhoff B, Martens J, Berger MM, Lobenwein C, Stankov MV, Cornberg M, David S, Behrens GMN, Witzke O, Blasczyk R, Eiz-Vesper B. COVID-19 immune signatures reveal stable antiviral $\mathrm{T}$ cell function despite declining humoral responses. Immunity 2021;54(2):340-354.e6.

[11] Hartzell S, Bin S, Benedetti C, Haverly M, Gallon L, Zaza G, Riella LV, Menon MC, Florman S, Rahman AH, Leech JM, Heeger PS, Cravedi P. Evidence of potent humoral immune activity in COVID-19-infected kidney transplant recipients. American journal of transplantation: official journal of the American Society of Transplantation and the American Society of Transplant Surgeons 2020;20(11):3149-61.

[12] Cortese I, Muranski P, Enose-Akahata Y, Ha SK, Smith B, Monaco M, Ryschkewitsch C, Major EO, Ohayon J, Schindler MK, Beck E, Reoma LB, Jacobson S, Reich DS, Nath A. Pembrolizumab Treatment for Progressive Multifocal Leukoencephalopathy. N Engl J Med 2019;380(17):1597-605.
[13] Migliori E, Chang M, Muranski P. Restoring antiviral immunity with adoptive transfer of ex-vivo generated T cells. Curr Opin Hematol 2018;25(6):486-93.

[14] Gaunt ER, Hardie A, Claas ECJ, Simmonds P, Templeton KE. Epidemiology and Clinical Presentations of the Four Human Coronaviruses 229E, HKU1, NL63, and OC43 Detected over 3 Years Using a Novel Multiplex Real-Time PCR Method. Journal of Clinical Microbiology 2010;48(8):2940-7.

[15] Ogimi C, Greninger AL, Waghmare AA, Kuypers JM, Shean RC, Xie H, Leisenring WM Stevens-Ayers TL, Jerome KR, Englund JA, Boeckh M. Prolonged Shedding of Human Coronavirus in Hematopoietic Cell Transplant Recipients: Risk Factors and Viral Genome Evolution. The Journal of infectious diseases 2017;216(2):203-9.

[16] Hutspardol S, Essa M, Richardson S, Schechter T, Ali M, Krueger J, Fujii H, Egeler RM, Gassas A. Significant Transplantation-Related Mortality from Respiratory Virus Infections within the First One Hundred Days in Children after Hematopoietic Stem Cell Transplantation. Biology of blood and marrow transplantation: journal of the American Society for Blood and Marrow Transplantation 2015;21(10):1802-7.

[17] Linenberger M, Fertrin KY. Updates on the diagnosis and management of the most common hereditary porphyrias: AIP and EPP, Hematology. American Society of Hematology. Education Program 2020;2020(1):400-10.

[18] Sette A, Crotty S. Adaptive immunity to SARS-CoV-2 and COVID-19. Cell 2021;184 (4):861-80.

[19] Keller MD, Harris KM, Jensen-Wachspress MA, Kankate VV, Lang H, Lazarski CA, Durkee-Shock J, Lee PH, Chaudhry K, Webber K, Datar A, Terpilowski M, Reynolds EK, Stevenson EM, Val S, Shancer Z, Zhang N, Ulrey R, Ekanem U, Stanojevic M Geiger A, Liang H, Hoq F, Abraham AA, Hanley PJ, Cruz CR, Ferrer K, Dropulic L, Gangler K, Burbelo PD, Jones RB, Cohen JI, Bollard CM. SARS-CoV-2-specific T cells are rapidly expanded for therapeutic use and target conserved regions of the membrane protein. Blood 2020;136(25):2905-17.

[20] de Sanctis V, Canatan D, Corrons JLV, Karimi M, Daar S, Kattamis C, Soliman AT, Wali Y, Alkindi S, Huseynov V, Nasibova A, Tiryaki TO, Evim MS, Gunes AM, Karakas Z, Christou S, Campisi S, Zarei T, Khater D, Oymak Y, Kaleva V, Stoyanova D, Banchev A, Galati MC Yassin MA, Kakar S, Skafida M, Kilinc Y, Alyaarubi S, Verdiyevas N, Stoeva I, Raiola G, Mariannis D, Ruggiero L, Di Maio S. Preliminary Data on COVID-19 in Patients with Hemoglobinopathies: A Multicentre ICET-A Study. Mediterranean journal of hematology and infectious diseases 2020;12(1):e2020046.

[21] Meyerholz DK, Perlman S. Does common cold coronavirus infection protect against severe SARS-CoV-2 disease? J Clin Invest 2021;131(1):e144807.

[22] Sagar M, Reifler K, Rossi M, Miller NS, Sinha P, White LF, Mizgerd JP. Recent endemic coronavirus infection is associated with less-severe COVID-19. J Clin Invest 2021;131(1):e143380.

[23] Anderson EM, Goodwin EC, Verma A, Arevalo CP, Bolton MJ, Weirick ME, Gouma S, McAllister CM, Christensen SR, Weaver J, Hicks P, Manzoni TB, Oniyide O, Ramage $\mathrm{H}$, Mathew D, Baxter AE, Oldridge DA, Greenplate AR, Wu JE, Alanio C, D'Andrea K, Kuthuru O, Dougherty J, Pattekar A, Kim J, Han N, Apostolidis SA, Huang AC, Vella LA, Kuri-Cervantes L, Pampena MB, Unit UPCP, Betts MR, Wherry EJ, Meyer NJ, Cherry S, Bates P, Rader DJ, Hensley SE. Seasonal human coronavirus antibodies are boosted upon SARS-CoV-2 infection but not associated with protection. Cell 2021;184(7):1858-1864.e10. 